\title{
Normal and Expanded Huntington's Disease Gene Alleles Produce Distinguishable Proteins Due to Translation Across the CAG Repeat
}

\author{
Francesca Persichetti,* Christine M. Ambrose,* Pei Ge, ${ }^{\dagger}$ \\ Sandra M. McNeil,* Jayalakshmi Srinidhi,* \\ Mary Anne Anderson,* Barbara Jenkins,* Glenn T. Barnes,* \\ Mabel P. Duyao,* Lisa Kanaley, ${ }^{\neq}$Nancy S. Wexler, $\$$ \\ Richard H. Myers," Edward D. Bird, $\neq$ Jean-Paul Vonsattel, ${ }^{\dagger}$ \\ Marcy E. MacDonald,* and James F. Gusella** \\ *Molecular Neurogenetics Unit, Massachusetts General Hospital, \\ Charlestown, Massachusetts, U.S.A. \\ 'Laboratory for Molecular Neuropathology, Massachusetts General \\ Hospital, Charlestown, Massachusetts, U.S.A. \\ ${ }^{\ddagger}$ Brain Tissue Resource Center, McLean Hospital, Belmont, \\ Massachusetts, U.S.A. \\ ${ }^{\S}$ Hereditary Disease Foundation, Santa Monica, California, U.S.A. \\ "Department of Neurology, Boston University Medical School, Boston, \\ Massachusetts, U.S.A. \\ \#Department of Genetics, Harvard Medical School, Boston, \\ Massachusetts, U.S.A.
}

\section{ABSTRACT}

Background: An expanded CAG trinucleotide repeat is the genetic trigger of neuronal degeneration in Huntington's disease (HD), but its mode of action has yet to be discovered. The sequence of the HD gene places the CAG repeat near the $5^{\prime}$ end in a region where it may be translated as a variable polyglutamine segment in the protein product, huntingtin.

Materials and Methods: Antisera directed at amino acid stretches predicted by the DNA sequence upstream and downstream of the CAG repeat were used in Western blot and immunohistochemical analyses to examine huntingtin expression from the normal and the HD allele in lymphoblastoid cells and postmortem brain tissue.
\end{abstract}

Results: CAG repeat segments of both normal and expanded HD alleles are indeed translated, as part of a discrete $\sim 350-\mathrm{kD}$ protein that is found primarily in the cytosol. The difference in the length of the N-terminal polyglutamine segment is sufficient to distinguish normal and HD huntingtin in a Western blot assay.

Conclusions: The HD mutation does not eliminate expression of the HD gene but instead produces an altered protein with an expanded polyglutamine stretch near the $\mathrm{N}$ terminus. Thus, HD pathogenesis is probably triggered by an effect at the level of huntingtin protein.

Address correspondence and reprint requests to: James F. Gusella, Molecular Neurogenetics Unit, Massachusetts General Hospital East, Building 149, 13th Street, Charlestown, MA 02129-2060, U.S.A. 


\section{INTRODUCTION}

Huntington's disease (HD) is an inherited neurodegenerative disorder characterized by progressive choreic movements, psychiatric changes, and cognitive decline $(1,2)$. These manifestations result from neuronal cell death, principally in the basal ganglia, where medium spiny neurons are the most vulnerable targets. Within the neostriatum, cell loss follows a characteristic gradient proceeding along the postero-anterior, dorsoventral, and medio-lateral axes (3). HD affects about 1 in 10,000 individuals in the United States and is caused by a dominant genetic defect that was mapped to $4 \mathrm{pl} 6.3$ by linkage analysis (4) and recently identified by location cloning (5).

Virtually all individuals with authenticated HD possess an unstable, expanded CAG trinucleotide repeat (reviewed in Refs. 6 and 7). In normal individuals, this repeat is polymorphic, varying from 6 to 34 trinucleotide units, and is inherited in a mendelian fashion. By contrast, the CAG repeat on disease chromosomes comprises 37 to more than 120 units, and shows a mutation rate approaching 1 through meiotic transmission. CAG repeat length is inversely correlated with age at onset of both neurologic and psychiatric symptoms, and with age at death. Most individuals show onset in mid-life due to repeat lengths in the range of 40-50 units, with a minority displaying either juvenile onset (typically $>60$ units) or onset very late in life (usually 37-40 units).

The mechanism whereby CAG repeat expansion causes neuronal death has not been established, but a number of observations favor an effect at the level of huntingtin, the HD gene's protein product (8). Huntingtin mRNA is not expressed exclusively or even preferentially in the affected brain regions, but is present in all tissues tested (9-11). RNA is produced from both normal and disease alleles, and contains the CAG repeat segment. Thus, the expanded CAG repeat is most likely to affect production of huntingtin from the disease allele, or to alter its structure, localization, or activity $(5,6,12)$. We have used antisera directed against potential translated sequences both upstream and downstream of the CAG repeat to investigate the expression of huntingtin from normal and HD alleles. Our data establish that the CAG segment is indeed translated into a predicted polymorphic polyglutamine stretch near the $\mathrm{N}$ terminus of huntingtin. The expanded repeat of the disease allele does not eliminate production of this $\sim 350-\mathrm{kD}$ protein. Rather, the additional glutamine residues contributed by the mutation make the HD huntingtin larger than, and therefore distinguishable from, its normal counterpart.

\section{MATERIALS AND METHODS}

\section{Peptides, Fusion Proteins, and Polyclonal Antibody Production}

PeptidesHPI (PAVAEEPLHRPKKELSATKKDRVN HCLTICENIV; residues $80-113$ based on L27416 in GenBank) and HP12 (ATLEKLMKAFESLKSF; residues 2-17) were synthesized and purified by The Peptide Laboratory, Inc. (Berkeley, CA, U.S.A.), or Multiple Peptide Systems (San Diego, CA, U.S.A.). A 1.8 -kb BamHI restriction fragment from the IT15B cDNA was subcloned into the pGEX vector (Pharmacia, Piscataway, $\mathrm{NJ}$ ) to express a $92-\mathrm{kD}$ huntingtin glutathione S-transferase fusion protein (huntingtin residues 19812580 ) in Escherichia coli. Polyclonal rabbit antisera were raised to keyhole limpet hemocyanin $(\mathrm{KLH})$-coupled peptides and the purified fusion protein by Assay Research, Inc. (MD, U.S.A.), and East Acres Biologicals (Southbridge, MA, U.S.A.). Preimmune sera were obtained before the immunization protocol was initiated (13).

\section{Cultured Lymphoblast Cell Lines and Postmortem Human Brain Tissue}

Lymphoblast cell lines from HD families of various ethnic backgrounds used for genetic linkage, and disequilibrium studies $(14,15)$ have been established (16) in the laboratory. Human postmortem brain tissue was collected by the Brain Tissue Resource Center, McLean Hospital (Belmont, MA, U.S.A.). At autopsy, one hemisphere of the brain was fixed and used for the evaluation of HD neuropathology according to the grading system devised by Vonsattel (3). The other hemisphere was dissected into small blocks of tissue representing various brain regions.

\section{DNA Extraction and HD CAG Repeat Length Determination}

DNA was prepared from cultured cells and from postmortem cerebellar brain tissue as described previously (4). The length of HD CAG alleles was assessed using polymerase chain reaction (PCR) amplification of the CAG stretch (17), excluding 
the polymorphic CCG repeat adjacent to the CAG (18).

\section{Protein Extraction and Cellular Fractionation}

Protein extracts were made from lymphoblast cell pellets and fresh postmortem brain tissue by homogenization in the presence of protease inhibitors (1 mM DTT, $1 \mathrm{mM}$ phenylmethanesulfonyl fluoride [PMSF], $0.1 \%$ leupeptin, and $0.1 \%$ aprotinin) in hypotonic lysis buffer containing $10 \mathrm{mM}$ Hepes $\mathrm{pH} 8.3,1.5 \mathrm{mM}$ magnesium chloride (19), or $50 \mathrm{mM}$ Tris $\mathrm{pH} 7.5,10 \%$ glycerol, $5 \mathrm{mM}$ magnesium acetate, $0.2 \mathrm{mM}$ EDTA (20), respectively. Protein concentrations were determined with the Protein Assay Kit (Bio-RAD, Richmond, CA).

Subcellular fractions were produced by differential centrifugation of cell lysates. Nuclei were collected by centrifugation at $2000 \mathrm{rpm}$ and extracted in nuclear extraction buffer containing $30 \mathrm{mM}$ Hepes pH 8.3, $0.3 \mathrm{mM}$ EDTA, $450 \mathrm{mM}$ sodium chloride, $12 \mathrm{mM}$ magnesium chloride, 1 mM PMSF, $1 \mathrm{mM}$ DTT, $0.1 \%$ leupeptin, and $0.1 \%$ aprotinin to produce the soluble nuclear fraction $(\mathrm{N})$. The postnuclear supernatant (PN), was fractionated by centrifugation at $100,000 \times$ $g$ to produce the $100,000 \times g$ supernatant, $S 100$ $(\mathrm{S})$, and the $100,000 \times g$ pellet Pl00 (P).

\section{Western Blotting}

Extracts $(\sim 200 \mu \mathrm{g}$ of protein) in sample loading buffer $(62.5 \mathrm{mM}$ Tris $\mathrm{HCl} \mathrm{pH}$ 6.8, $1 \%$ SDS, 0.15 $\mathrm{mg} / \mathrm{ml}$ bromophenol blue dye, $5 \%$ glycerol, $2.5 \% 2$ mercaptoethanol) were subjected to electrophoresis in SDS running buffer (25 mM Tris base, $192 \mathrm{mM}$ glycine, and $0.1 \%$ SDS) for $15 \mathrm{hr}$ at $70 \mathrm{~V}$ on a $6 \%$ polyacrylamide gel or for the separation of normal and HD huntingtin at $95 \mathrm{~V}$ on a $5 \%$ gel. Rainbow high molecular weight range protein markers, 14.3-200 kD (Amersham Corp., Arlington Heights, IL, U.S.A.) were also loaded on each gel. Proteins were transferred to nitrocellulose membrane by electroblotting at $30 \mathrm{~V}$ for $6 \mathrm{hr}$ in $25 \mathrm{mM}$ Tris base, $192 \mathrm{mM}$ glycine, and $20 \%$ methanol.

For immunoblot analysis, Western blot membranes were preincubated with TBST (20 $\mathrm{mM}$ Tris $\mathrm{HCl} \mathrm{pH} \mathrm{8.0,} 150 \mathrm{mM} \mathrm{NaCl}, 0.1 \%$ Tween 20) supplemented with dry milk powder and then probed with the primary rabbit antibody for $2 \mathrm{hr}$. The specific interactions were visualized with biotinylated horseradish peroxidase cou- pled anti-rabbit immunoglobulin (VECTASTAIN $\mathrm{ABC}$ kit) using the enhanced chemiluminescence (ECL) Western Blotting Detection System Kit (Amersham) according to the instructions of the manufacturer. Blots were exposed to X-ray film (XAR, Kodak, Rochester, NY, U.S.A.).

\section{Immunohistochemistry}

Human postmortem brain tissue was dissected, fixed in $4 \%$ paraformadehyde and cryoprotected in sucrose. Frozen 7- $\mu \mathrm{M}$ cryostat sections, mounted on gelatin subbed slides, were processed for immunohistochemistry using standard protocols (21). Immune complexes were detected using the avidin-biotin method employing biotinylated horseradish peroxidase $\mathrm{H}$ and diaminobenzidine substrate (VECTASTAIN ABC kit) according to the instructions of the manufacturer (Vector Laboratories, Inc., Burlingame, CA). The immunostained sections were dehydrated and counterstained with hematoxylin. Microphotographs were taken with Ektachrome $64 \mathrm{~T}$ slide film at a magnification of $630 \times$.

\section{RESULTS}

\section{The HD CAG Repeat Is Translated}

Huntingtin mRNA contains a long open reading frame with the polymorphic CAG segment near its $5^{\prime}$ end. Translation from a potential initiator ATG located 17 codons upstream of the CAG would predict a large product of $\sim 3130$ residues with a mass of $\sim 350 \mathrm{kD}$. If translation were initiated downstream at the first potential inframe ATG after the CAG repeat, a smaller product of 3014 amino acids with a mass of $333 \mathrm{kD}$ would be predicted. To determine whether the CAG segment is translated, we prepared rabbit polyclonal antisera against two peptides, and one bacterial fusion protein representing different portions of the largest predicted product. The antipeptide antisera, HPl and HP12, are directed against amino acids 80-113 and 2-17, respectively (based on L27416 and L12392). Antiserum HF1 was prepared using amino acids $1981-2580$ expressed in E. coli as a fusion with glutathioneS-transferase (GST).

Figure 1 shows the results of Western blot analyses of normal and HD lymphoblastoid cell extracts using HP1, HP12, and HF1. In Panel A, all three immune sera detect a large $\sim 350-\mathrm{kD}$ protein that is not revealed by their correspond- 
A

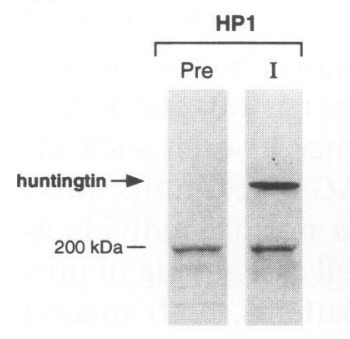

C

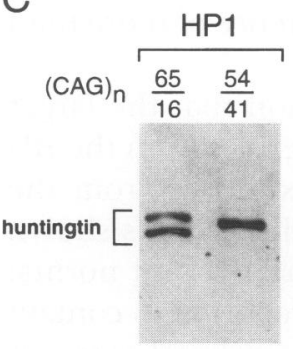

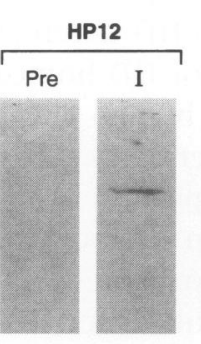

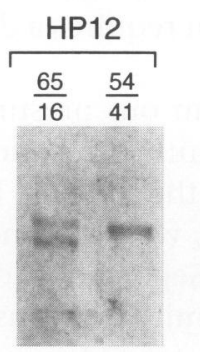

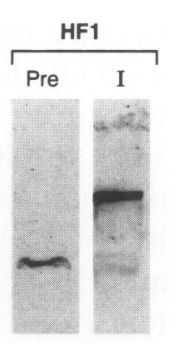

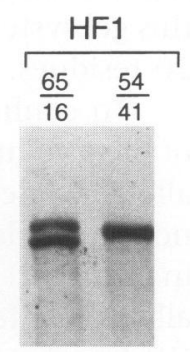

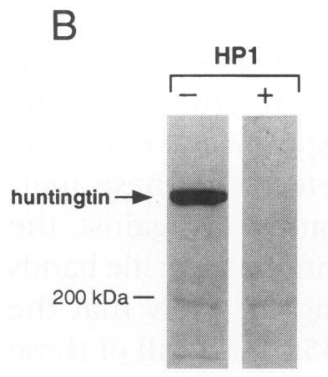
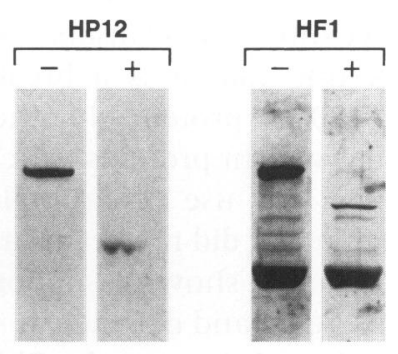

FIG. 1. Antisera specific for different portions of huntingtin detect a $\sim 350 \mathrm{kDa}$ protein in lymphoblast cells

(A) Detection of huntingtin. Identical Western blot panels of lymphoblastoid cell protein extracts were probed with preimmune (Pre) or immune (I) sera. The left-hand panel shows the results obtained with a 1:500 dilution of antipeptide serum HP1; the central panel, with 1:500 dilution of anti-peptide serum HP12; and the right-hand panel, a $1: 10,000$ dilution of anti-fusion protein HFl. The position of the $200-\mathrm{kD}$ molecular weight standard (myosin) is shown. The identity of the $\sim 200-\mathrm{kD}$ protein band detected by the preimmune and immune rabbit sera is not known but also serves as a convenient marker protein in human lymphoblast protein extracts. The position of the huntingtin band detected in both lanes of each panel by the immune sera is indicated and is estimated to be $\sim 350$ $\mathrm{kD}$. (B) Detection of huntingtin is abolished by preincubation with antigen. Identical Western blot panels of lymphoblast protein extract were probed with immune sera at the concentrations given in Panel A with (+) or without (-) preabsorption of each antiserum (HP1, HP12, and HF1) with $12 \mu \mathrm{g} / \mathrm{ml}$ of its corresponding immunogen. The positions of the $200-\mathrm{kD}$ marker protein (myosin) and of the specifically competed $\sim 350$-kD huntingtin protein are indicated. The right-hand panel was deliberately overexposed to visualize the $\sim 250-\mathrm{kD}$ putative huntingtin breakdown product that is also competed by immunogen. This band is located between two nonspecific bands of similar intensity that are not competed. (C) HD huntingtin is distinguishable from normal huntingtin. Identical Western blot panels of lymphoblast protein extracts from HD heterozygotes (Lane 1) and HD homozygotes (Lane 2) were probed with a 1:500 dilution of HP1 (left-hand panel) and HP12 (central panel), and 1:10,000 dilution of HFI (right-hand panel). The length of the polymorphic CAG stretch in the DNA of each individual was determined by PCR analysis and is shown above each lane as the estimated number of CAG repeat units, $(C A G)_{n}$. The position of the $200-\mathrm{kD}$ marker (myosin) is shown and the products of the normal and HD alleles, located close to each other at $\sim 350 \mathrm{kD}$, are denoted by a square bracket.

ing preimmune sera. Both the immune and preimmune HP1 and HF1 sera also detect a band at $\sim 200 \mathrm{kD}$ that varies in intensity in different extracts. This nonspecific band (see below) is detected by most other rabbit antisera that we have tested, and may be myosin.

The specificity of detection of the protein bands was tested by preabsorption of each immune serum with its corresponding antigen, an example of which is shown in Fig. 1B. In all three cases, incubation with the corresponding immunogen specifically eliminates the reactivity to the $\sim 350-\mathrm{kD}$ protein. This reactivity is not removed by preincubation with high concentra- tions of bovine serum albumin (data not shown). Preabsorption with immunogen does not eliminate reactivity to the nonspecific $\sim 200$-kD protein detected by both immune and preimmune sera. Deliberate overexposure of the HFl blots in Fig. $1 \mathrm{~B}$ reveals the presence two intense bands, the specific $350-\mathrm{kD}$ huntingtin band and the nonspecific $\sim 200-\mathrm{kD}$ band, along with three lighter bands of intermediate size. The larger and smaller of these intermediate bands are nonspecific, as they are not removed by preabsorption of the antiserum with immunogen. However, the remaining intermediate band, which we estimate at $\sim 250 \mathrm{kD}$, is specifically removed by preab- 
sorption. The presence of this band and its relative intensity is variable across experiments, suggesting that it is a breakdown product of the $\sim 350-\mathrm{kD}$ protein. No other specific lower molecular weight proteins were detected in these analyses and use of multiple antisera against the same blot did not reveal additional specific bands (data not shown), supporting the view that the discrete band detected at $\sim 350 \mathrm{kD}$ by all of these antisera is huntingtin. This notion is also corroborated by immunoprecipitation of huntingtin from ${ }^{35} \mathrm{~S}$-labeled lymphoblast extracts using HP1 and HFl (data not shown). The fact that huntingtin is detected using antisera directed against predicted epitopes both upstream and downstream of the CAG repeat indicates that the trinucleotide segment is translated in a frame predicted to produce a lengthy stretch of polyglutamine.

\section{The HD Mutation Does Not Eliminate Huntingtin Expression}

Huntington's disease displays a completely dominant clinical phenotype, as evidenced by a number of individuals who are homozygous for the disease allele $(22,23)$. Lymphoblast cell lines from such individuals make it possible to demonstrate directly expression of huntingtin from the mutant allele. For example, in Fig. 1C, HP1, HP12, and HFl all detect huntingtin in an HD homozygote with CAG repeat lengths of 41 and 54 on the two disease chromosomes.

Interestingly, not only is huntingtin produced from the HD allele, but the HD huntingtin can also be distinguished from normal huntingtin based on its electrophoretic mobility. For example, Fig. 1C also shows typical results for an HD heterozygote (with a disease allele of 65 CAGs and a normal allele of 16 CAGs). All three antisera detect the same two protein species from this individual, suggesting that the allelic products differ significantly in their migration due to the difference in the length of the polyglutamine stretch. The predicted difference between HD and normal huntingtin is $<1 \%$ in almost all $\mathrm{HD}$ cases and $<3 \%$ in even the most severe juvenile onset cases. It has been noted previously that changes in the length of polyglutamine stretches can cause disproportionate changes in the migration of the proteins that contain them $(H$. T. M. Timmers, personal communication). We have optimized gel conditions to favor the separation of very large proteins and have consistently found that heterozygous HD patients reveal two distinct huntingtin bands. In all cases, detection is prevented by preincubation with immunogen. In contrast to HD heterozygotes, neither normal individuals nor HD homozygotes reveal two distinct protein bands. The latter is not surprising, since the interallelic difference in each such individual is typically $<15$ CAG repeat units. Mixing of protein extracts from normal individuals and HD homozygotes, as well as assaying of protein from adult onset HD patients, both suggest that resolution of distinct huntingtin bands in this gel system requires a difference of more than 20 residues.

To confirm our presumption that the larger of the two huntingtin bands derives from the HD allele, while the smaller is expressed from the normal allele, we performed the analysis shown in Figure 2. Segregation of the HD and normal alleles in a family previously reported to contain HD homozygotes (22) is compared with analysis of huntingtin in corresponding lymphoblast protein extracts. As expected, progeny with only the normal alleles (16/20 CAG repeat units) display a single huntingtin band. Progeny with two disease alleles (49/43,55/48, and 54/41 units) yield a single huntingtin band that is larger than normal huntingtin. Heterozygous individuals, including both offspring (44/16 units) and parent (45/16 units), exhibit two huntingtin bands. The smaller band is similar in size to that seen in normals and the larger band similar to that seen in the HD homozygotes. Thus, the CAG segment in the open reading frame of the $H D$ gene is translated from both normal and HD alleles consistent with the defect having its deleterious effects at the protein level.

Northern blot and in situ hybridization studies have suggested that huntingtin is expressed in most or all tissues. To determine whether the protein could be detected in the target tissue of $\mathrm{HD}$, we performed prepared Western blots for various areas of postmortem normal human brain. Figure 3A shows typical results for freshly collected caudate/putamen, temporal cortex and frontal cortex, all of which reveal the same size band seen in normal lymphoblasts. The two different isoforms of huntingtin in an HD heterozygote are also detectable in freshly collected postmortem brain tissue (Fig. 3B).

\section{Huntingtin Is a Primarily Cytosolic Protein}

We have performed cell fractionation experiments to determine whether the structural alteration in HD huntingtin affects the cellular localization of the protein. Figure $4 \mathrm{~A}$ shows an 


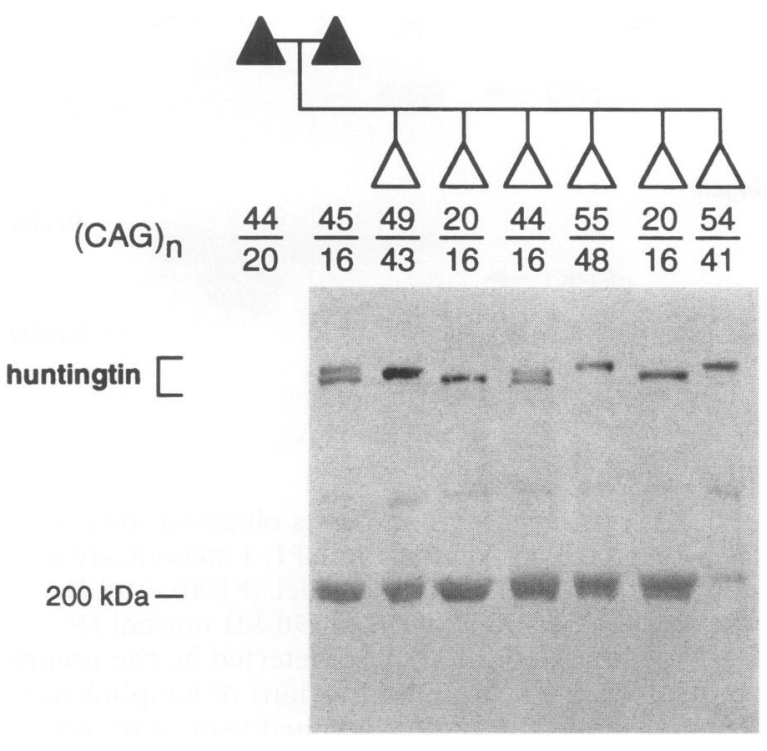

FIG. 2. Inheritance of HD and normal huntingtin in a sibship previously reported to contain HD homozygotes

A Western blot of lymphoblast protein extracts from members of a sibship from the Venezuelan HD pedigree in which both parents are affected by HD (22) (filled symbols) was probed with a $1: 10,000$ dilution of HFl. Birth order and the sex of the parents and progeny have been disguised for confidentiality. The estimated number of CAG repeat units, $(C A G)_{n}$, is given above each lane. Protein extracts from both parents were found to exhibit both normal and HD huntingtin bands in separate Western blot experiments but only the genotyping is given here for one of the parents. The position of the $200-\mathrm{kD}$ marker (myosin) is shown, and the positions of normal and $\mathrm{HD}$ huntingtin at $\sim 350 \mathrm{kD}$ are indicated by the square bracket.

example of Western blot analysis of cell fractions produced from normal and HD lymphoblasts by differential centrifugation. The cell fractions were tested for huntingtin and for the distribution of several control proteins (Fig. 4B). As expected, HD huntingtin migrated more slowly than normal huntingtin.

Huntingtin is found primarily in the cytosol (S100) fraction when fractionation of either normal or HD homozygous lymphoblasts is performed in the absence of added salt or detergent. Very little protein is detected in the nuclear fractions (including both nucleosol and nuclear pellet preparations), even upon long exposures of the blots. A small proportion of huntingtin does pellet from the cytoplasmic fraction at $100,000 \times$ $g$ (P100 fraction). This minor component can be shifted into the S100 cytosolic fraction by frac-

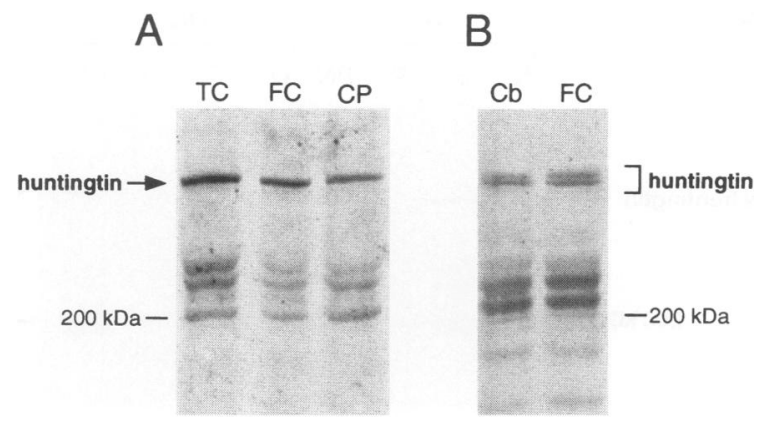

FIG. 3. Detection of normal and HD huntingtin in human postmortem brain extracts

(A) Normal human brain. A Western blot of proteins extracted from dissected regions of a control human postmortem brain; temporal cortex (TC), frontal cortex $(\mathrm{FC})$, and caudate and putamen $(\mathrm{CP})$ were probed with $1: 10,000$ dilution of HFl. Preabsorption of the immune antiserum with HFl fusion protein specifically eliminated the huntingtin band, and the additional bands were also detected by the preimmune serum (data not shown). The positions of the 200-kD marker (myosin) and of the huntingtin band are shown. (B) HD brain. A Western blot of proteins extracted from dissected regions of a grade $4 \mathrm{HD}$ postmortem brain; cerebellum $(\mathrm{Cb})$ and frontal cortex $(\mathrm{FC})$ were probed with a 1:10,000 dilution of HFl. PCR analysis revealed that this individual carried a normal CAG allele of 18 repeat units and an expanded HD CAG allele of 41 repeats. The position of the 200-kD marker (myosin) is shown and the products of the normal and HD alleles, located close to each other at $\sim 350 \mathrm{kD}$, are denoted by a square bracket.

tionation in the presence of increasing salt concentrations, suggesting that its association with a pelletable element is relatively weak. No differences were observed between normal and HD homozygous cells, indicating that the fractionation characteristics of huntingtin are not altered by the presence of the HD defect.

The cytoplasmic location of huntingtin was confirmed by immunohistochemical analysis of normal and HD tissues. A preliminary survey of our antisera indicated that the preimmune sera did not yield significant staining and that, of the immune sera, only HFl exhibited reproducible staining. Because of the reactivity of HFl serum with the nonspecific $200-\mathrm{kD}$ band on Western blots (Fig. 1A and B), we tested the huntingtin specificity of the immunohistochemical staining by preabsorption with immunogen. Figure 5A shows a typical example of the distribution achieved in frontal cortex (in this case from an HD heterozygote). Both neuronal cell bodies and neuropil are stained by anti-huntingtin antisera, 
A

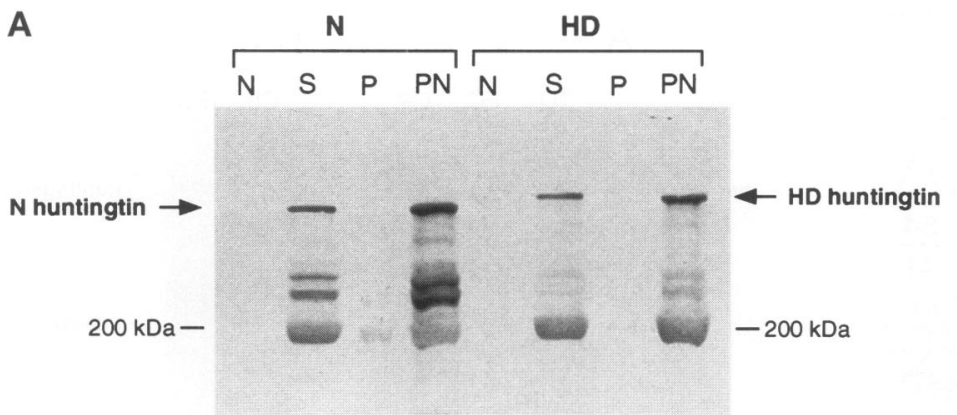

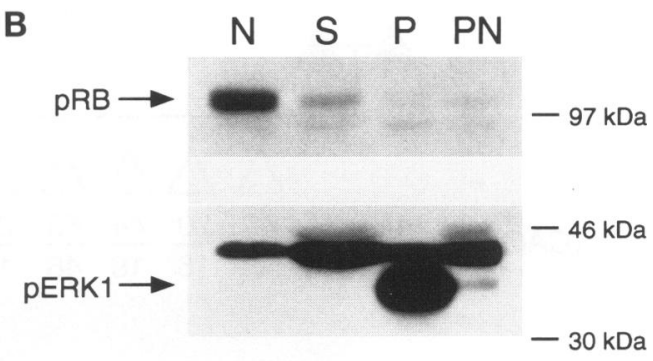

FIG. 4. Huntingtin is located in the cytosolic fraction of lymphoblast cells

(A) Detection of huntingtin. A Western blot of proteins in subcellular fractions of lymphoblasts obtained from a normal individual (N) and an HD homozygote (HD) was probed with a 1:10,000 dilution of HFl. Fractions are denoted by PN, postnuclear supernatant; $S, 100,000 \times g$ supernatant $(S 100) ; \mathrm{P}, 100,000 \times g$ pellet $(\mathrm{Pl} 100)$, and $N$, nucleosol. The position of the $200-\mathrm{kD}$ marker (myosin) is shown, and the positions of the $\sim 350-\mathrm{kD}$ normal $(\mathrm{N}$ ) and HD (HD) huntingtin are indicated by arrows. The bands at $\sim 240$ and $\sim 260 \mathrm{kD}$ are also detected by the preimmune sera. (B) Detection of control proteins. Western blots of proteins in the subcellular fractions of lymphoblasts shown in Panel A were probed with control antibodies. The top panel shows the results obtained using a monoclonal antibody directed at $\mathrm{pRB}$, a $110-\mathrm{kD}$ nuclear protein that is detected in the $\mathrm{N}$ fraction (24), and the bottom panel the results with a monoclonal antibody directed at pERKI (Transduction Laboratories), a 44-kD plasma membrane associated protein that is detected in the $\mathrm{P}$ fraction (25). The band at $\sim 45 \mathrm{kD}$ is probably a phosphorylated form of ERKl that is also recognized by this monoclonal. In separate experiments (not shown), similar Western blots were probed with polyclonal rabbit antisera against ornithine aminotransferase (OAT), a mitochondrial protein (26) that was detected in the P fraction and neurofibromin (27), a cytoplasmic protein that can associate with microtubules that was found in both the P and S fractions (28).

and this signal is effectively removed by preabsorption (Fig. 5B). The location of huntingtin is most easily seen in large neurons where the antisera stain the cytoplasm but not the nuclei. As expected from the cell fractionation studies, no difference in the intracellular distribution of huntingtin was seen between normal and HD heterozygote cells in these experiments (data not shown).

\section{DISCUSSION}

The discovery that HD is caused by an expanded, unstable CAG trinucleotide repeat has provided an explanation for many of the genetic features of the disorder, but the mechanism by which this peculiar defect leads to specific neuronal cell death remains obscure. Initial data argue against an effect on transcription, prompting us to explore potential mechanisms at the RNA and protein levels using huntingtin-specific antisera. From sequence analysis alone, it is not been possible to distinguish whether translation of huntingtin mRNA begins upstream of the CAG repeat, to produce a product of $>3130$ amino acids with a variable polyglutamine segment near the $\mathrm{N}$ terminus, or downstream from the CAG stretch to produce a smaller protein devoid of polyglutamine. Neither can the sequence predict whether the expanded CAG segment on disease chromosomes eliminates translation of the mRNA or alters the start site for translation. The immunological studies reported here clearly establish that alleles bearing the disease-producing expansion continue to express a protein product, since cells from HD homozygotes also possess huntingtin. Furthermore, the detection of huntingtin as a $\sim 350-\mathrm{kD}$ protein by antibodies directed against peptides predicted from both upstream and downstream sequences confirms that the CAG repeat is translated from both normal and $\mathrm{HD}$ alleles as a long polyglutamine tract.

The detection of a single large protein species in normal individuals is consistent with the absence of alternatively spliced mRNAs from this locus and suggests that huntingtin is neither processed to a smaller functional unit nor subject to extensive heterogeneous modifications that affect its migration. The only other specific band on Western blots, detected occasionally at $\sim 250 \mathrm{kD}$, probably represents a breakdown product produced during preparation of protein extracts. Thus, these antisera provide no immediate evidence for other proteins arising from related members of a gene family. 

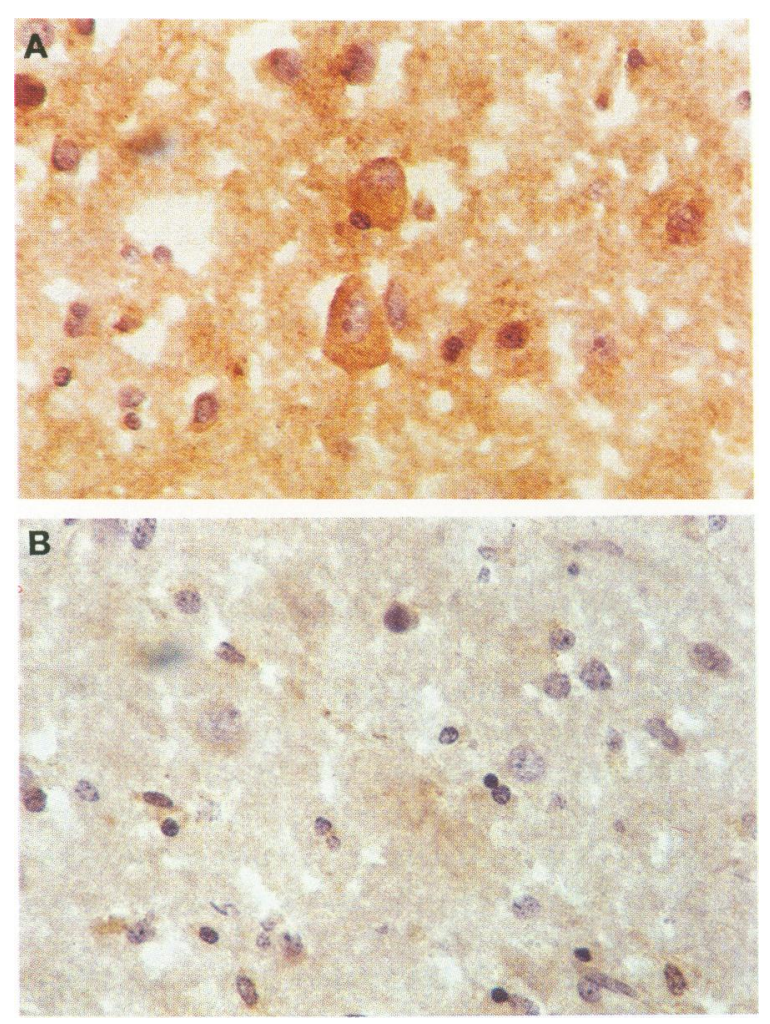

FIG. 5. Immunohistochemical detection of huntingtin in HD brain

(A) Huntingtin expression. A cryostat section of frontal cortex from an HD grade 3 postmortem brain was immunostained for huntingtin using a 1:1000 dilution of HF1 immune serum $(630 \times)$. The section is counterstained with hematoxylin. (B) Detection of huntingtin is abolished by preincubation with antigen. A section of HD frontal cortex nearly adjacent to that shown in Panel A was immunostained with HFl immune sera that had been preabsorbed with $12 \mu \mathrm{g} / \mathrm{ml}$ of HFl fusion protein (as in Fig. 1B) $(630 \times)$. The section is counterstained with hematoxylin.

The presence of an expanded CAG segment is associated with an HD huntingtin that is detectably larger than the normal isoform. The relative migration of the protein varies with the length of the CAG stretch. Normal and HD huntingtins cosegregate in families with normal and HD alleles, respectively, demonstrating directly the origin of each protein band. Our gel system does not allow us to resolve either individual normal alleles or HD alleles in typical homozygotes, since a difference of $\sim 20$ residues is required. Thus, although protein analysis could theoretically be used to diagnose the presence of an HD allele, it cannot currently resolve all four alleles in a mating and is inferior to direct DNA analysis. The basis for the disproportionate contribution of additional glutamines in reducing the electrophoretic mobility of huntingtin is not obvious, but this phenomenon has also been observed for smaller proteins (H. T. M. Timmers, personal communication). Consequently, additional investigation might lead to a method of separating huntingtin products from alleles differing by fewer than 20 CAG units.

Our investigations also demonstrate clearly that both normal and HD isoforms of huntingtin are cytoplasmic proteins. The only previous investigation of huntingtin's cellular location was an immunohistochemical analysis using a single C-terminal anti-peptide antiserum (29). This yielded variable results, staining either exclusively cytoplasm in most cells or both cytoplasm and nucleus in lymphoblasts and neurons. Both our Western blot and immunohistochemical analyses failed to corroborate the suggestion of nuclear localization, implying that the previously reported variable nuclear staining may have been due to specific conditions that allowed shuttling of the protein or at least its C-terminal portion into the nucleus in some cells, or may have been spurious. Our detection of huntingtin exclusively in the cytoplasm of both normal and $\mathrm{HD}$ cells indicates that the expanded polyglutamine segment does not to alter the protein's cellular compartment. However, more detailed studies at the EM level could conceivably reveal regional differences in distribution of normal and HD huntingtin within the cytoplasm.

The translation of the CAG repeat into a polyglutamine segment in huntingtin strengthens the view that the defect acts at the protein level. Possible mechanisms include inappropriate cellular expression or intracellular localization, increased activity, a dominant negative effect, or a gain of function. Any hypothesis ultimately must also account for the specificity of cell death and the strong correlation between repeat length and disease severity.

Neither HD mRNA in situ hybridization studies nor preliminary immunohistochemical analysis have suggested a flagrant abnormality in the pattern of huntingtin expression in HD brain $(9-11,29)$, although more detailed studies in a variety of cells and tissues during development might still reveal significant differences. Both increased activity of HD huntingtin and a dominant negative effect of the mutation represent hypotheses that cannot be tested directly, since no function has yet been ascribed to the protein. The gain-of-function scenario, which is particu- 
larly attractive, could involve the formation of a toxic byproduct from HD huntingtin, or a novel interaction with another cytoplasmic component. The latter would explain the cellular specificity of the pathogenesis if the abnormal interaction occurred with a protein peculiar to striatal neurons.

An important difference between the gainof-function hypothesis and the other potential models is that in the former, the pathogenic mechanism might operate without any detrimental effects on huntingtin's normal activity. For example, this contrasts directly with the dominant negative hypothesis which presumes a loss of huntingtin's activity and places a premium on discovering the normal role for this protein. These two opposing mechanisms may be distinguished by manipulation of the mouse $H d h$ gene, either to inactivate it or to introduce an expanded CAG segment. It is hoped that at least one of the two will yield an accurate genetic model for dissecting the steps by which production of HD huntingtin leads to specific neuronal death.

\section{ACKNOWLEDGMENTS}

We thank Drs. J. Settleman, S. Pillai, V. Ramesh, E. Harlow, A. Bernards, S. Reeves, and H. T. M. Timmers for supplying control antisera and for helpful discussion and the Brain Tissue Resource Center (McLean Hospital) for postmortem tissues and clinical information. This work was supported by National Institutes of Health Grants NS16367, NS22031, and NS32765, and by grants from Bristol-Myers Squibb, Inc., the Hereditary Disease Foundation, and the Huntington's Disease Society of America. CA was supported by the Andrew B. Cogan Fellowship of the Hereditary Disease Foundation, and SM and MD were supported by fellowships from the Huntington's Disease Society of America and the Hereditary Disease Foundation, respectively.

\section{REFERENCES}

1. Martin JB, Gusella JF. (1986) Huntington's disease: Pathogenesis and management. $N$. Engl. J. Med. 315: 1267-1276.

2. Folstein SE. (1989) Huntington's Disease. A disorder of families. The Johns Hopkins University Press, Baltimore.

3. Vonsattel JP, Myers RH, Stevens TJ, Ferrante RJ, Bird ED, Richardson Jr EP. (1985) Neu- ropathological classification of Huntington's disease. J. Neurol. Exp. Neuropath. 44: 559577.

4. Gusella JF, Wexler NS, Conneally PM, et al. (1983) A polymorphic DNA marker genetically linked to Huntington's disease. Nature 306: 234-238.

5. Huntington's Disease Collaborative Research Group. (1993) A novel gene containing a trinucleotide repeat that is expanded and unstable on Huntington's disease chromosomes. Cell 72: 971-983.

6. Gusella JF, MacDonald ME, Ambrose CM, Duyao MP. (1993) Molecular genetics of Huntington's disease. Arch. Neurol. 50: 11571163.

7. Gusella JF, MacDonald ME. Huntington's disease. Semin. Cell Biol. 1, in press.

8. Ambrose CM, Duyao MP, Barnes G, et al. (1994) Structure and expression of the Huntington's disease gene: Evidence against simple inactivation due to an expanded CAG repeat. Somat. Cell Mol. Genet. 20: 27-38.

9. Strong TV, Tagle DA, Valdes JM, et al. (1993) Widespread expression of the human and rat Huntington's disease gene in brain and nonneuronal tissues. Nature Genet. 5: 259-265.

10. Li SH, Schilling G, Young III WS, et al. (1993) Huntington's disease gene (IT15) is widely expressed in human and rat tissues. Neuron 11: 985-993.

11. Landwehrmeyer BG, McNeil SM, Ge P, et al. (in press) Huntington's disease gene: Expression in brain of normal and affected individuals. Annals Neurol.

12. MacDonald ME, Ambrose CM, Duyao MP, Gusella JF. (1993) Capturing a CAGey killer. In: Genome Analysis. Vol. 7, Genome Rearrangement and Stability. Cold Spring Harbor Laboratory Press, New York, pp. 25-41.

13. Harlow E, Lane D. Antibodies, A Laboratory Manual. (1988) Cold Spring Harbor Laboratory Press, New York.

14. MacDonald ME, Lin C, Srinidhi L, et al. (1991) Complex patterns of linkage disequilibrium in the Huntington disease region. Am. J. Hum. Genet. 49: 723-734.

15. MacDonald ME, Novelletto A, Lin C, et al. (1992) The Huntington's disease candidate region exhibits many different haplotypes. Nature Genet. 1: 99-103.

16. Anderson M, Gusella JF. (1984) Use of clyclosporin A in establishing Epstein-Barr virus-transformed human lymphoblastoid cell lines. In Vitro 20: 856-858. 
17. Warner JP, Barron LH, Brock DJ. (1993) A new polymerase chain reaction (PCR) assay for the trinucleotide repeat that is unstable and expanded on Huntington's disease chromosomes. Mol. Cell. Probes 7: 235-239.

18. Rubinsztein DC, Leggo J, Barton DE, Ferguson-Smith MA. (1993) Site of CCG polymorphism in the HD gene. Nature Genet. 5: $214-$ 215.

19. Miner LL, Pandalai SP, Weisberg EP, Sell SL, Kovacs DM, Kaplan BB. (1992) Cold-induced alterations in the binding of adrenomedullary nuclear proteins to the promoter region of the tyrosine hydroxylase gene. $J$. Neurosci. Res. 33: 10-18.

20. Dignam JD. (1990) Preparation of extracts from higher eukaryotes. In: Deutscher MP (ed). Guide to Protein Purification. Vol. 182, Methods in Enzymology. Academic Press, New York, pp. 194-203.

21. Hockfield S, Carlson S, Evans C, Levitt P, Pintar J, Silberstein L. (1993) Selected methods for antibody and nucleic acid probes. In: Molecular Probes of the Nervous System. Cold Spring Harbor Laboratory Press, New York. Vol. 1, pp. 111-226.

22. Wexler NS, Young AB, Tanzi RE, et al. (1987) Homozygotes for Huntington's disease. Nature 326: 194-197.

Contributed by S. H. Orkin on March 17, 1995.
23. Myers RH, Leavitt J, Farrer LA, et al. (1989) Homozygote for Huntington's disease. Am. J. Hum. Genet. 45: 615-618.

24. Hu QJ, Bautista C, Edwards GM, DefeoJones D, Jones RE, Harlow E. (1991) Antibodies specific for the human retinoblastoma protein identify a family of related polypeptides. Mol. Cell Biol. 11: 5792-5799.

25. Marquardt B, Stabel S. (1992) Sequence of a rat cDNA encoding the ERKl-MAP kinase. Gene 120: 297-299.

26. Mueckler MM, Pitot HC. (1985) Sequence of the precursor to rat ornithine aminotransferase deduced from a cDNA clone. J. Biol. Chem. 260: 12993-12997.

27. The I, Murthy AE, Hannigan GE, et al. (1993) Neurofibromatosis type 1 gene mutations in neuroblastoma. Nature Genet. 3: 62-66.

28. Golubic M, Roudebush M, Dobrowolski S, Wolfman A, Stacey DW. (1992) Catalytic properties, tissue and intracellular distribution of neurofibromin. Oncogene 7: 21512159.

29. Hoogeveen AT, Willemsen R, Meyer N, et al. (1993) Characterization and localization of the Huntington's disease gene product. Hum. Mol. Genet. 2: 2069-2073. 